\title{
How to Make a Story Beautiful: On Aesthetic Dialectics of Liao zhai zhi yi
}

\author{
LI Hong-xiang \\ East China Normal University, Shanghai, China
}

\begin{abstract}
How to write a beautiful story? It is an important question to Chinese writers because novel has not been regarded as a formal genre until late Qing Dynasty. Pu Songling answers this question with his work Liao zhai zhi yi (Strange tales from a Chinese studio). This paper aims to study his narrative arts. There are four sections included. In part 1, this paper introduces a definition of the aesthetic dialectics and its embodiment in Chinese classical literary theory; in part 2, this paper takes the Liao zhai story as example to interpret Pu Songling's dialectic relation between description and narration; in part 3, I will show how Liao zhai presents beauty by unexpected but reasonable changes; and in last part, I give more importance to the stories concerning ordinary things for the reason that Pu Songling could make them interesting and beautiful. In the end, the paper concludes that Pu Songling is successful storyteller by using dialectic arts, which should be learned by Chinese writers.
\end{abstract}

Keywords: Liao zhai, beauty, change, aesthetic dialectics, narration

\section{Introduction}

How can a story be made beautiful? That is an important question to a Chinese author. Because the novel has not been respected sufficiently by Chinese classical intellectuals as in the West, the study of novel accordingly lacks enough attention. This question is becoming highlighted with the development and spread of the Chinese novel in modern times.

One early response to this question is to beautify the story in the way of Chinese poetry. It is a convention for a Chinese classical novelist to put poems at the beginning or the end of story. Nevertheless, the poems function as the introduction or comment about the story instead of beautifying it. Sometimes, the author added poems in the procedure of narration, but their role is expressing the author's talent of writing poetry rather than telling a story. The poems in a story are often separated from the whole story. At best, like A Dream in Red Mansions written by Cao Xueqin, the author took beautiful images from Chinese classical poems in description of scenery, behavior or decoration of home furnishing. However, the poetic characteristic in the novel seems obvious to the readers who are familiar to Chinese classical poems. They can be understood so easily that causes the story looks somewhat unreal. That is to say, Chinese novelists did not know how to match a poem to the story so that the story and poem make up an organic system. This case became serious in late Qing Dynasty when more and more intellectuals began to get interested in writing novels. This is how Feng Zhenluan criticized the novelists at that time: "Recently, in the field of novel writing, what the novelists preferred to

LI Hong-xiang is an Associate Professor at International College of Chinese Studies, East China Normal University. My interest covers Chinese literature and thoughts, ancient Greek tragedies, aesthetic perception and contemporary image culture. 
writing story is inserting beautiful words from $\mathrm{Ci}$ and $\mathrm{Fu}$, two kinds of Chinese classical poem into their novel so as to express their emotion, modify the ancient events or show off their literature talent and the abundance of knowledge” (Zhang, 2011). Likewise, Fu Xueqiao indicated the same defect in the preface of Wei Zi'an's novel Hиа yue hen: "Although many famous writers are good at writing $\mathrm{Ci}$ and $\mathrm{Fu}$, they are not skillful in the respect of narration. So it is very sad and boring to see that every time when they dealt with details in the description of emotion or scenery, they use the $\mathrm{Ci}$ and Fu" (Kong, 1982). These two quotations demonstrate that how to write the beautiful story is indeed a serious question to a Chinese novelist.

However, we shouldn't draw the conclusion so quickly therefore that Chinese novelists did not know how to write beautiful story. Pu Songling, the author of Liao zhai zhi yi (Strange tales from a Chinese studio), gives us a successful example. In his beautiful stories, he seldom used the poem to beautify his story; rather, relying on narrative arts themselves we can find the answer to the question mentioned at the outset. In this paper, my aim is to take Liao zhai as an example to light up how Pu Songling narrated a story in a beautiful way. And concretely speaking, I will focus on the aesthetic dialectics deployed in Pu's stories and investigate how it is related to the Chinese narrative tradition that affects Pu Songling's writing. I will answer this question in following four sections: in part 1 , I will introduce a definition of the aesthetic dialectics and its embodiment in Chinese classical literary theory; in the next part, I will take the Liao zhai story as example to interpret how Liao zhai story is made beautiful by means of a dialectic relation between the description of things and narration of action which was applied; part 3, I will show how Liao zhai presents beauty by unexpected but reasonable changes; and in the last section, I give more importance to the stories concerning ordinary things for the reason that Pu Songling could make them interesting and beautiful by means of the dialectic changes of conflicts in life.

\section{Part 1 Dialectics in Chinese Aesthetics}

The conception of aesthetic dialectics here I am talking about is not what one modern ideologist thinks about in his mind. It only refers to a method of aesthetic show to make things beautiful. The reason that I want to introduce the method is to solve the aesthetic problem in Chinese novel.

The earliest thought about aesthetic dialectics derives from the ancient Chinese classics. In the oldest Chinese classic, I Ching, or The Book of Changes, the name of I indicates three contrastive meanings: one refers to the change, one refers to the constancy and the other refers the easy or simple. This phenomenon of three kinds of different or contrastive meanings in one word reflects the characteristics of Chinese thought. According to I Ching, the beauty is the pleasure of body experience caused by the smooth change, the organic unity or fine balance between the contrastive aspects of Yin and Yang. ${ }^{1}$ Likewise, the Daoism classic Laozi also indicates that true beauty, other than beauty in the common sense, should come from no-action (wu-wei), in which the flowing, natural and creative Tao is presented. And in philosophy, it can be described in the form constituted by the mutually contrastive but unified categories of being and non-being, the difficult and the easy, the long and the short, the high and the low. As Laozi has said in Tao-techjing (classic of the way and its virtue):

When the people of the world all know beauty as beauty,

\footnotetext{
${ }^{1}$ In I Ching, wenyan about the Kun Diagram, we can see the Confucian interpretation about beauty. Other than the beautiful appearance, beauty is the pleasure caused by the open, free and smooth change state, which is represented in human body, mind and social action.
} 
There arises the recognition of ugliness.

When they all know the good as good,

There arises the recognition of evil.

Therefore:

Being and non-being produce each other... (Chan, 1963)

The dialectic thought in both I Ching and Tao-teching reflects the oldest feature of Chinese aesthetics. Comparing with two books' description of the truth from objective aspect, Zhuangzi implied in a metaphorical way that the truth of Dao comes from the ecstatic state, i.e., the highly focused state of spiritual existence, while the ecstatic experience is understood as the recognition of beauty. ${ }^{2}$ And Zhuangzi described in qi wu lun, the dream and reality could not be figured out clearly in an ecstatic state.

Chinese philosophy has known very early how to make things beautiful by means of dialectics and how to apply it to the Chinese classical literature theory. There are many different concepts concerning the standard of beauty in the history of Chinese classical literature theory. Confucian's Wu xie ${ }^{3}$ and Taoist's Truth should be the earliest two ideas. Subsequently, the literary theorists such as Zhong Rong, Lu Ji and Liu Xie, etc., in South and North Dynasty put forward the theory of Ziwei (taste) regarding the olfactory or gustatory experience, and the painter Xie He took the "qi yun sheng dong" as the first rule of painting. The concept of "qi yun" means the vividness or vigor like the flow of "qi", in the work, which is developed in later Chinese literary terms such as Wang Changling and Sikong Tu's “yi jing” in Tang Dynasty, Yan Yu’s “miao wu” in Southern Song Dynasty, Wang Shizhen’s “shen yun”4 and Wang Guowei’s “jing jie” in Qing Dynasty. All of these concepts, although in different terminology, indicate nothing more than that beauty exists in the inner experience of body. It is very hard to make it clear in words but understandable by human's body experience.

What does the beauty mean in terms of these concepts in aesthetic or literary theory? As Zhuangzi said, a true man is the one who can clean his spirit and obey the law of things, and the true beauty therefore should be the thing in itself. Other than the thing in physical view, the thing here denotes lively existence in the living world, which can be understandable in the open and clear state. Instead of expressing the subjective emotion directly, to the poet the beautiful poem should be implicit but understandable by how it presents the thing. As Wang Guowei indicated that the highest criterion of a poem is to create the state in which the world of thing without "me" in view of its being is understandable (Wang, 1960). The dialectics is just a method describing the state or the world of things. As the painter Jing Hao, Han Zhuo talked about “yun” of the landscape painting: to reach the state of so called "yun", the landscape should be painted in a form combining concealment yet revelation as well, which could make the painting extraordinary. ${ }^{5}$ And it is not surprising that the dialectic

\footnotetext{
${ }^{2}$ In Zhuangzi, there is a story about the true painting. Song yuanjun asked the painter to paint for him. When most of the painters stood in the yard waiting to paint, however, there was a painter coming, he did not care about others, entering into the room directly. Latter, unexpectedly, he was found to be naked in the room. After Song knew about this, he sighed that it is the true painting.

${ }^{3}$ Wu xie, selected from Lu song in the classical work of Shi Ching, means the spiritual state of openness or sincerity to the world. According the idea of Lu song, this concept originally expresses the attitude to the god in the ancestor worship ceremony, whereas, it was explained later from the moral aspect by Confucius.

${ }^{4}$ It is very coincident that Wang Shizhen is the first important critic of Liao zhai zhi yi. Nevertheless, he seemed not to give sufficient attention to this book, and only wrote to Pu Songling a poem in which he commented that the book could be regarded as a play work expressing the author's desire.

5 Actually, it is always supposed that the beautiful work should be like poetry, $\mathrm{Ci}$ and Fu required to be implicit in description of things. However, few novelists can do this, in fact, clear and detailed narration and description is always regarded as necessary for a novel. See Feng Zhenluan's comments about Liaozhai. Although he admitted that one of important properties of this work is its detail in things, it is because he broke the aesthetic criteria that Pu Songling did not obtain proper evaluation in his life.
} 
relation between the lightening and the shadowing, concealment and revelation is also regarded as the property of truth in art works pursued by the 20th century existentialist philosopher Heidegger (Heidegger, 1971).

\section{Part 2 The Narration in Action and Description of Things}

Question is the dialectic method in Chinese aesthetics mostly deployed in verse such as poetry or $\mathrm{Ci} \mathrm{Fu}$ instead of the novel. The novel did not get sufficient attention by Chinese intellectuals until the late Qing Dynasty. Although there are many novels, there is not a systematic novel theory like the classical poetics accordingly which aims to improve the aesthetic quality. What authors of these stories seemed to care more about entertaining themselves rather than making their stories beautiful. They did not know how to render the story beautiful as the classical poets did, and when they confronted such trouble, what they thought about was only to insert poems into the story. Just as I mentioned at the outset, this problem got very serious in late Qing Dynasty. Why did the Chinese novelists pay less attention to the beauty of novel? There are two reasons. In wen yan novel written in classical language, because Chinese intellectuals are biased against the genre of novel and take the novel just as a tool of entertainment, so they lack sufficient interest to modify the story as they do their poems. In baihua novel in local oral language, which is derived from alive performance, it seems not necessary to make it beautiful. A beautiful work, firstly, should rest on the presentation of the thing itself in the world. In Chinese classical poetry, the poet can present the real world in way of description of things that occurred in character's situation. The description of things in poetry is the way to make the poem beautiful because it can express the author's feelings and thoughts implicitly. Because the description of scenery might slow down the rhythm of narration, for the purpose of live performance, the description of things is always very simple or stereotyped. The storyteller just presents the event mainly constituted by the dramatic plot and vivid image of character. This case highlights the significance of Liao zhai in Chinese novel history. Pu Songling spent most of his life writing stories not for entertainment but to express his depressed feelings in reality. ${ }^{6}$ Comparing with the novel before and after, especially the works of the same kind about strange things, Liao zhai is a beautiful work written in a poetic way instead of simply inserting the poems. What is the most obvious characteristic is its description of things.

Generally speaking, the question how to make the novel beautiful concerns two sides including both the narration of action and the description of things. According to Chinese narrative experience in classical poetics, these two sides are neither fixed nor separated with each other. On the contrary, they are dialectic constituents of a flow of events. The description of the thing should go with the narration of procedure of action and the narration should proceed with the changes of things. The dialectic relation of the narration of action and description of things is similar to being and non-being, making the story poetic.

Here is an example of the story Wang Shi xiu in which there occurred an event related to Wang Shixiu's experience on Dongting Lake in Hunan province. First is the night scenery perceived by Wang Shixiu when he stopped the boat on the lake, i.e., the moon is rising up and the lake is like white silk. Then the people on the other boat entered his eyes. Their clothes looked strange absolutely, but because the moonlight was so blurring it is hard for him to figure them out clearly. What he got is just the sound that they urged each other to drink more. Then the viewpoint turned to Wang Shixiu, who stayed in the boat, scared, and dared not move a little.

\footnotetext{
${ }^{6}$ There are two literature works as the most important representatives of the Chinese intellectual novel in Chinese classical literature history: one is the long story The Red Mansion and the other is the collection of short stories Liao zhai zhi yi, which are always regarded as the king of Chinese short novels.
} 
The whole procedure proceeded according to Wang Shixiu's subjective experience in the event, in which the light of the moon, the color of clothes and the sound of talking and urging to drink were well narrated subsequently in the living logical order. It is for this description of things in order that the event was endowed fully with the sense of beauty. In Wang Gui'an, there is a paragraph in which Pu Songling described Wang's experience in dream.

Some six months passed away thus, and then, having exhausted all his funds, he was obliged to go home, where he remained in a state of general inaptitude for anything. One night he dreamed that he entered a village on the river-bank, and that, after passing several houses, he saw one with a door towards the south, and a palisade of bamboos inside. Thinking it was a garden, he walked in, and beheld a beautiful magnolia, covered with blossoms, which reminded him of the line: And Judas-tree in flower before the door.

A few steps farther on was a neat bamboo hedge, on the other side of which, towards the north, he found a small house, with three columns, the door of which was locked; and another, towards the south, with its window shaded by the broad leaves of a plantain-tree. The door was barred by a clothes-horse, on which was hanging an embroidered petticoat; and, on seeing this, Wang stepped back, knowing that he had got to the ladies' quarters; but his presence had already been noticed inside, and, in another moment, out came his heroine of the boat. Overjoyed at seeing her, he was on the point of grasping her hand, when suddenly the girl's father arrived, and, in his consternation, Wang woke up, and found that it was all a dream. Every incident of it, however, remained clear and distinct in his mind, and he took care to say nothing about it to anybody, for fear of destroying its reality (Giles, 2010).

In this paragraph, what Wang Gui'an experienced in dream was described like what happened in the real world. Pu Songling narrated the whole procedure including entering the village, passing the house and thinking of the line. Following Wang's track as he walked, Pu Songling described the beautiful things that Wang saw, heard and felt in Wang's position. From the far to the near, from the outside to the inside, everything which appeared in Wang 's action was vivid and well arranged in order like what the author would experience by himself.

The beautiful things described in the action can strengthen the sensation of reality and improve the story's aesthetic quality as well. Comparing the beautiful things described in the event, Pu Songling tended to create in the story an implicit aura of emptiness by means of the description of things at the end of the event. In Wang Gui'an, for instance, the character was sitting on the boat together with his wife one evening, making a joke with his wife by saying: “you have fallen into my snare after all.” To increase a little pressure, he added, "For I can't conceal from you much longer the fact that I have already a wife, belonging to a high official family.” He did not expect that his wife suddenly jumped up and ran out of the cabin. He shouted out to boats to come to their assistance, the story described what he saw as follows: nothing was to be seen in the river, save only the reflection of the stars shining brightly on the water. Comparing with the nervous and noisy atmosphere after the boat girl jumped into river, what rose in Wang's eyes at this moment was empty and nothing that could be focused on; however, it is just because of the emptiness of non-being, there is something poetic occurred.

In Ghost in River, Pu Songling demonstrated his keen sensibility and extraordinary talent in description. Wang Shengyu traveled southward. One night, he moored his boat in the center of river. Seeing the moonlight lighting like white silk, he could not fall asleep and had the houseboy signaled to him. At that moment, everything seemed quiet, relaxing and peaceful. Unexpectedly, something occurred suddenly. Wang heard a sound like a child's walking on the cabin top; subsequently the sound moved from to the stern to the bow so 
that Wang Shengyu feared that there might be thieves coming. When he saw a man bending on the top of cabin and snooping inside, he became scared and screamed aloud which woke everyone up. At the beginning, all of them thought that should be his illusion until they heard a big sound raised somewhere. Pu Songling described what they saw as follows: "everyone looked around and saw nothing but sprinkling stars, bright moon and endless waves of river." Comparing with the mystical sound that Wang Shengyu heard in the cabin, what he saw is really non-beings. The way of scenery description is the same as the case in Wang Gui'an. Although Pu Songling did not write what Wang Shengyu and others were feeling, however, there are some complicated feelings such as anxiety, terror and pleasure, etc., presented in the beautiful things he saw.

The emptiness of things is one constituent of the beauty; precisely speaking, the dialectic relation between the detailed narration of action and empty description of things made it beautiful. It is the technique of poetry employed generally in the Liao zhai story. Pu Songling used partially in Wang Gui'an and ghost in river, whereas in double lanterns, the author fulfilled the whole story with poetic sense relying on a poetic structure. At the beginning of the story, Wei Yunwang was lying in bed alone at night, when he heard the sound of footsteps outside approaching from far to near. The sound of footsteps began more and more intense until two bright red lanterns picked by two maidservants appeared suddenly in front of him. At the end of the story, when the mysterious girl bid farewell to Wei and was escorted to leave the village, the similar impressive image of red lantern appeared again. Nonetheless, this is a sad time to leave so that the perceived content of image is different from what it is at the beginning. The red lantern is described from both Wei's perceptive and others' like this: Wei stood there for a long time with grief, watching the red lanterns flickering far away until they were lost in his eyes. Then he returned his home sadly. And just at that night, every body in the village saw that red fire lightening far away on the top of the mountain. From the image of red lantern that appeared so closed to Wei to the same image so far away, during this period, what happened are not only the temporal and spatial relation between Wei and the girl, but also the changes of emotional experience from the scare to love, from pleasure to sadness. Especially in dealing with the last scenery, Pu Songling took the viewpoint to a distance to put the red lanterns far away until everything was lost in darkness. The contrast between the red lantern image of being in the beginning and non-being at the end of the story, when the double lanterns slowly disappeared in darkness, the atmosphere of sadness becomes gentle and plain, which produces a charming aura in the work that is hard to express in words. The beautiful world Pu Songling made in the work of double lanterns is very similar to what is presented in Chinese classical $\mathrm{Ci}$, qing bei le, written by Zhang Xian in the North Song Dynasty.
It is the time to wake up, but I am still drunk, I am watching far away and feeling sad. So, change wine cups frequently for more.
To north and west many times, I return to pond, Without caring for spring I hate the lotus scattered.
The lantern is going to bid farewell.
Who knows that there are guests leaving banquet, See the double singers disappearing far away. It is late when the boat came back in the vaporous river.

From the method of description in qing bei le, it seems that Pu Songling has grasped the skill needed to make story beautiful in a poetic way rather than with the help of poem. Actually, Pu Songling could deploy the 
poetic technique rather freely in his story by noting the emptiness of things at the end of the story. In Pian Pian, after Luo Zifu departed from Pian Pian, he missed her very much and took his children to see her. However, when he approached the cave where a romantic story had occurred before, there was nothing but yellow leaves on the road and a white cloud in front of the cave. So he had to return sadly in tears. In Lady in green, to thank Yu Jing for his life-saving grace, at the moment of leaving the green honeybee climbed into the ink stone and immersed herself in the black ink. After she climbed out, she bent to the table and wrote a Chinese character “谢” with her body, then flew away through the window. In Gong sun Jiu niang, Mr. Lai yang missed Gong sun Jiu niang very much. One day after half a year, he saw Jiu niang far away near the tomb. He dismounted his horse and wanted to talk to her. However, the lady seemed not knowing Mr. Lai yang and walked away silently. When Mr. Lai yang tried to get close to the lady, she got very angry and hid her face with the sleeves. Mr. Lai yang became very worried instantly and shouted "Jiu niang"; however, the lady disappeared unexpectedly at that moment. Similarly, in wu tong, Mr. Jin at sixty years old went to the dragon palace accompanied with fairy Xia gu. Originally, the experience is just supplements the story, to verify what the fairy told to him. However, Pu Songling did not deal with the section easily, on the contrary, he narrated it through the Jin's perceptive by which the scenery seems moving beautifully like this: one day, when Jin was crossing the river, looking at a big lotus leaf like a mat far way floating on the river and on the lotus leaf there sat a beautiful girl. Getting close to watch, he found that it is the fairy. Then he jumped on the lotus leaf and went with the fairy. The two men with lotus leaf became smaller and smaller until they were like a coin and disappeared at last. This kind of technique of dealing with the end of a story, i.e., from the near to the far, from the beings to the empty in the eyes of the character is very like what is pictured in a famous sentence in the poem written by Qian Qi, a poet in Tang Dynasty, saying: "The music is over, nobody can be seen, but several mountains on the river," which affords the work a subtle and provoking sensibility.

\section{Part 3 The Beauty From Changes}

As has said, change is supposed to be the nature of the world, and the dialectics reflects the world of change from which the true beauty is presented. The so-called strange story precisely denotes the change story. The body and the soul, the reality and dream, the human being and supernatural powers are the changing forms. ${ }^{7}$ What Liao zhai distinguishes from others is not the strange or ridiculous, but amazing and reasonable changes.

The early critic Fen Zhenluan indicated that the sense of reality based on emotional logic is an extraordinary property of Liao zhai: It is said that it is much easier to tell the story of ghost and more difficult to tell the story of the tiger compared with telling the story of human being, because the ghost has no moral sense while the tiger has character. Where it is hard to speak about the ghost, people can imagine some events to make it real; while it is hard to speak about the tiger, it is useless to do the same as with the ghost. I did not think so. To say so the ghost story needs also to present the logic of human emotion. Just like the saying said, "A lie needs also to be theoretically self-consistent which is so called the logic of emotional and moral sense." To speak about the ghost and fox in Liao zhai in this way is to speak about them according to the logic of human's emotion and ethic and thing's characteristics. The highest realm of telling lie is not out of human's emotional logic and the most advanced skill, similarly it is precisely within human's expectation. Although in

\footnotetext{
${ }^{7}$ From this point, Pu Songling's Liao zhai can be said to be the Chinese version of Ovid's Metamorphoseonlibri.
} 
many places the author was deliberate to supplement extra imaginative plots for the purpose of the reality of story, but I would like to see that he made them so logical without obviously drawing a forced analogy. In this way Liao zhai story could be widespread and appreciated extensively (Zhang, 2011).

Likewise, the modern novelist Lu Xun noted also that, besides the detailed plot in narration, Liao zhai story represented secular emotion. Mostly, the monster of flower or fox has human feelings which made them amiable and easy to approach. Their true identity is always forgotten. Only in the place where abnormal change occurs suddenly was their inhuman nature exposed. Both of them figured out the reasonable change as its important feature.

Here, I intend to proceed to explain further on how Pu Songling rendered his work beautiful by means of reasonable change. The most representative work about change is the story about the wandering soul. Such stories have a long history in China, most of which are narrated according to the order of time like the Tang romance li hun ji written by Chen Xuanyou. However, Pu Songling reformed the narrative model to a large extent. He always told something that occurred in reality and generally disclosed the truth either in the middle or at end of story that what the character had already experienced happened actually in the dream or in another world. In kao cheng huang (Examination for the post of guardian angel, translated by Giles), the first story in Liao zhai zhi yi, Song Tao was told by the king that a Cheng huang god lacked in He nan cheng huang temple, and he was just the most suitable person to take that position. Only then Song suddenly realized that he was dead and so cried for return. In Chu Suiliang (A supernatural wife, translated by Giles), it is at the end of story that the fox girl told the character that she was a fox fairy and he was the Chu Suiliang, a general in Tang Dynasty. What she had done for him was for paying a debt of gratitude. In ye sheng, Mr. Ye came to his home and found in sorrow that his house looked cold and bleak from outside. When he wandered into the yard, his wife with dustpan saw him and got so frightened as to run away by throwing what was in her hand. Mr. Ye said sadly to her, "I am rich and honored now, but why don't you know me. It is only three or four years since I left home after all." Mr. Ye's wife said to him in a distant place, "You have been dead for a long time and so what about you saying riches and honor?” In jiu kuang, Mr. Miu saw his uncle coming out from the room, asking him "where are you from?” Mr. Miu understood suddenly that he was dead because his uncle has been dead for years. In gu sheng, when Mr. Gu heard some sounds, he opened his eyes and found that the dogs were licking an oiled boiler in hotel, which reminded him that the drama he had experienced was really a dream. In hu meng, the fox girl escorted Bi Yi'an out of the village. After Mr. Bi woke up suddenly, he was conscious that what he experienced turned out to be a dream. However, to his surprise, he could feel a strong taste of wine in his nose and mouth. All of these non-reality stories are narrated in way of the reality, which often strikes readers when the real identity of characters is uncovered. But this kind of consequence does not appear as an accident; rather, the author has already put some clues at the beginning of story by which the consequence can be reached logically.

A narrative model used in general is that before the character's soul began to wander around, either he is going to die, or his spirit was so tortured by desires as to get sick or drunk which cause the character to enter an unusual state. What he experienced in the other world, including the dream or the underworld, seems to be the result of this spiritual state. In kao cheng huang, before Song Tao met the gods in the underworld, he was thinking hard of passing the exam; what he experienced just occurred at the moment when he was sick in bed. In Chu Suiliang, Mr. Zhao in Changshan was in the state of sickness and loneness before a beautiful fox girl visited him. In ye sheng, before Mr. Ye was going to die, he was pursuing riches and honor. In jiu kuang, Miu 
Yongding was going to die with cold limbs. In gu sheng, before Mr. Gu's soul entered the house, he was in a state of ecstasy. In story hu meng, before Bi Yi'an met the fox girl, he was entranced deeply by the novel qing feng so that every time he read it, he was looking forward to seeing a girl like Qing feng. Such and such stories about wandering soul look like strange fiction, nevertheless, are real in a psychological sense.

Liao zhai's world is full of amazing but reasonable changes. In order to highlight the aesthetic effect, $\mathrm{Pu}$ Songling tended to describe the sudden changes of beautiful things in his story. In Bai Yuyu about a beautiful fairy, when Fang was just preparing to ask for more, instantly Bai Yuyu became very small like a finger, crossing on the back of a cicada, flying away as far as in cloud at last. It seems not so surprising if the reader attends to some details about Bai Yuyu’s strange behavior in the procedure of communicating with Wu Qing'an. One is that when Bai Yuyu first appeared before $\mathrm{Wu}$, his horse looked like a dragon. The second case is that what Bai Yuyu read were the books that could be rarely seen at that time. The third is that every night when Bai invited Wu to drink, he would show him a book concerning the breathing art. Because it is too complicated, Wu put it aside. These three cases imply that Bai Yuyu is not an ordinary man. With regard to the breathing art, he might be like a Taoist or a fairy in Taoist's imagination, therefore, what he changed into later is naturally understandable. In Huang Ying about chrysanthemum, Mr. Tao and Mr. Ma both got drunk. Mr. Tao rose up and returned home. As Tao passed the field and stepped on the chrysanthemum, to Ma's great astonishment, Tao suddenly fell down and changed into a chrysanthemum that was tall like a man. As a result, the Tao and his sister's true identity of the monster of chrysanthemum were exposed. Whilst before their exposition, similarly, Pu Songling stated three unusual cases that occurred to Tao and his sister. First, when Tao helped Ma with planting chrysanthemum, all of the dead chrysanthemum could return to life after Tao Sheng pulled them out completely and planted them again. Second, the chrysanthemums abandoned by Ma were picked up again by Tao. They became excellent ones in Tao's hand and Tao therefore got rich after he sold them. Ma doubted Tao possessed the treasures privately and hated Tao for his greed and decided to criticize Tao, even planning to break off the relations with Tao. Unexpectedly, he later discovered that the chrysanthemum that Tao sold was just what he had given up. The third case was surprising as well. Ma went to Tao's home again the next day after drinking one night and found that the new-planted chrysanthemum grew up to a foot in height. All of these three things foreshadowed the sudden change of Taoist's image from human to the chrysanthemum. Because the author has provided enough information in different places to keep the logical coherence and identity, the sudden change is naturally reasonable.

The dialectics of unexpected but reasonable change of things is not only used in events concerning supernatural power, but also human life. Actually, Pu Songling made no difference between the supernatural and the human power. What he focused on was the dialectic rule embodied in everything. It can be said that it is the basic rule with which Pu Songling narrated all of the strange stories. Take a short story tai yi (Imperial doctor) as an example, Sun Pingshi was informed by the imperial doctor that he should not eat the meat of bear and tiger since he got serious sick, and he would die otherwise. At the beginning, nobody took care of the doctor's warning because these kinds of animal meat were very rare to see. Nonetheless, it is on the prince's birthday that the emperor took out the bear's paw in order for civil and military officials to enjoy in the celebration. The white bear's paw sliced with red wires tastes delicious. Sun did not know what it was and ate it up. Only the next day did he know from his colleagues that what he had eaten were bear's paw. He was frightened so that he died as soon as he returned home. What makes the story strange is that things go from the expected to the contrary direction. Such unexpected but fatal things committed by Sun Pingshi occur very often 
in real life. Pu Songling told many stories in a similar way. In yao seng (The monk who sold aphrodisiac), a certain in Ji Ning could resist the temptation in thinking that the more aphrodisiac he took, the stronger his sexual power became. Unexpectedly, because he ate too many medicines, his penis got too big so that he could not walk as usual and his parents did not recognize him as well. In ge yi (Strange pigeon), the white pigeon with the value of gold was sent to the high officer, unexpectedly, it was served as food for cooking and eating. In cheng su (Folk custom in Cheng), the local people of Cheng got out to look for food in the body of rat but all were killed instantly because the guests poured the water into the cave where they lived. In Chang zhi women, the master put a certain clever girl's spirit under his control by means of magical arts. He commanded the girl to investigate a case secretly in country government; however, at the moment when the officer took out the seal, the girl peeking on the beam suddenly felt very heavy and fell down in accident. In Sun Bizhen, when the crowd on the boat saw the golden signboard held by the god in gold armor on which there were three Chinese characters Sun Bizhen. They thought that Sun might be punished by a god and expelled him away to another boat. But surprisingly, after Sun boarded the ship, he looked back and found that the boat the crowd stayed on turned over.

What makes the changes happen so that they look reasonable? Other than in the strange stories of the same kind, Pu Songling's answer is the human's desire. The world of change is just a representation of nothing else but human desire. Motived by desire, change goes following the logic that where the emotion cannot be satisfied, the change occurs necessarily. This is just like what Gejin, a peony monster, said to Chang Dayong in story Ge Jin, "three years ago, to thank you for your love, I devoted myself to you; up to now, since you suspect me, there is no need to get together again.” At the end of this story, Pu Songling concluded his thought about change between the human and the supernatural as follows: "There is no obstacle between the human and the ghost or god if one has passion for love." Pu Songling expressed the same idea in his comments on the story Xiangyu "If one devotes his love to the extreme, he can communicate with the ghosts and the gods." It can be said that the strange story is exactly the love story and that change occurs because of love. We can understand this from two stories concerning tiger; one is miao sheng and the other is Xiang Gao. Mr. Miao could not bear the guests' endless boring talking and mutual admiration; suddenly he transformed himself as a tiger, catching and killing some of guests, roaring away at last. In Xiang Gao, for the purpose of revenge, Xiang Gao was transformed into a tiger with the help of a Taoist. The change of appearance was strange but true with respect to the emotion. Another story about tiger is zhao cheng $h u$. This is not a story of transformation but the relation between human and animal. An old woman was in deep sorrow because a tiger ate her only son. The women appealed to the court and hoped the officer had the tiger killed as compensation for her son. The officer laughed and said to the woman: "the tiger is an animal, how did we do with it in terms of human's official law?" Everybody was put in a quandary at the time and had to gather in temple to pray for god's help. However, what is strange is that the dangerous tiger came to the temple and actively received punishment, raising the woman like her son. It is therefore called the moral tiger. As officer judged in court, it is an ironclad law since old time that who kills others should be killed too. You killed the old woman's only son and on what can she continued to live? If you willing to be her son you will be free. Comparing his previous judgment, the officer's latter judge seems ridiculous prima facie, but is reasonable in terms of emotional logic based on the woman's desire. That is to say, the character's depressed desire in reality will be liberated and satisfied by means of dream. Once the reader attends to this logic, the impression caused by the sudden change could be well understood. 


\section{Part 4 The Beauty From Conflict in Life}

It is worth noting that although Liao zhai is always called the work of strange stories, in fact, in addition to the story about the strange things, especially concerning the supernatural powers like ghost or fox fairy, there are a lot of stories about ordinary things as well. Compared with the strange things, the real theme of such works seems too simple to stimulate the readers. ${ }^{8}$ So, it is not surprising that in the history of interpretation of Liao zhai, these stories are rarely talked about. But I would rather give more importance to these short stories because they are beautiful relying on the author's artistic talent instead of the strange property of things.

Then, how did Pu Songling make ordinary things beautiful? What he did was to present the contradiction of the thing in a simple but clear way. Here are three examples concerning the wolf. The drive is a short story about a wolf that took opportunity to bite flesh from a driver's leg when he was trying to push up his cart to the top of a slope. The story was told in realism instead of personification. What makes the story attractive is not about how cunning the wolf is, but the driver's contrastive situation. He had to tolerate both the pains of being bitten by the wolf and the labor of pushing the cart up at the same time. Otherwise the goods in cart might be destroyed. It is the contrastive situation that makes the driver's story both funny and sympathetic. The story, wolf and herd boys, is similar to driver but the character is changed. It is not the man but the wolf that bore the painful torture. Two herd boys found a lair with two little wolves in it. Seizing each of them one, they forthwith climbed two trees which stood there, at a distance of forty or fifty paces apart. They made fun of the distressed and angry mother wolf by pinching her cub to squeak respectively, diverting the wolf's attention, until the mother was dead tired, and lay down exhausted on the ground. Although as Pu Songling said, the story told that man could take his advantage to defeat the brute beasts; however, the amazement of the story does not rest on this. The point is the paradoxical emotions including the pains in the mother wolf's position and fun in the herd boys' position.

There is something in common in two stories, say, an ironic or contradicted emotion constituted by the painful and the funny, the innocent and the cruel, the horrible and the beautiful, the love and the hatred. Pu Songling demonstrated his insight of the paradoxical emotion in the reality of human life and the dialectic faculty in human's mind. The paradoxical emotions are fulfilled in his stories about ordinary things, by which his stories seem both mysterious and interesting. There are three stories with respect to snake: huan she (Snakes in temple), she pi (Eating snake) and she ren (The man who raises snake). These three stories vary in length, but the basic narrative form is similar to the story of wolf, all of which deal with paradoxical emotions. In huan she, the monks of a temple were enjoying their delicious dinner. The meat soup was delicious and each cut of meat was round like the neck of chicken, but unexpectedly, these relish foods were made of snakes. The scenery latter appeared was even more terrifying. It is astonishing for people to find that there were snakes on the wall, under the seat of the Buddha statue, in the well, and almost everywhere. The she pi is a short story within one hundred words, which is somewhat like a sketch of a painting. The form is simple but the effect is impressive, which is not because of the horror of snake but of the conflict between the pleased appearance on the face of snake-eater and the horrible eating-picture: once the little snake was obtained, all was immediately swallowed like biting shallots, whereas, given a bigger snake, it would be cut in inches, then crunched and its

\footnotetext{
${ }^{8}$ Although Liao zhai zhi yi is always called the strange stories, it is precisely a kind of work about what the author sees, hears and thinks about according to the tradition conception of strange books. Like Bo wu zhi written by Zhang Hua, it seems to be an encyclopedia instead of story work, even if it is also called the strange story.
} 
blood watering the eater's cheek. The last picture is especially horrible because, to imagine such a situation, without knife in hand, that the snake's head was bitten first in eater's mouth while its tail was still left swinging outside. The invisible snake's head by means of the visible bloody tail is more impressive in effect than the direct description would be. In contrast, the end of the story she ren seems a little bit gentle. This story's narrative power does rest not only on the friendship between two snakes but also on the change of contradictive emotion between the terror and the beauty. The snake appeared suddenly with a frightening storm but turned into a lovely state immediately after she found that the snake she met was her friend.

There are also some documentary stories, some of which are even like a piece of news report or a sketch of life scenery heard from others without the twist plots or descriptions of vivid character and scenery. Pu Songling still can make them real and amusing in terms of the principle of dialectics. In xi yi (Playing at Hanging), for instance, a young rogue originally in order to entertain a lady passing by, pretended to hang himself by the neck with a joke "I want to die" simultaneously. Beyond his expectation, he was really hung on the beam. The story of the Earthquake was reported about the true event which occurred in July 25, 1668. Pu Songling experienced the massive devastating earthquake by himself in Qi xia, Shandong province. However, what he emphasized was not his terrible experience, rather, a funny picture. Following the description about the collapse of the housing, the frightened and noisy mass, the author's visual angle turned to an interesting scene. Many people got together and talked about the earthquake on the street, whereas they were too hurry to wear clothes. Pu Songling displayed his imagination about details in this scene, trying to make the story funny. There was a woman who peed at night. When she looked back, she found that a wolf was dangling her son. She tried hard to fight with the wolf and took her son back finally. After the wolf escaped, she changed from fear to joy and told others gathering around about her thrilling experience how she snatched her son from the wolf's mouth. It was not until at last did she notice that she was naked. The author commented at the end of the story as this, "this case is similar to the earthquake in which the difference of man and women was forgotten. How it is funny to see that people lose their reason at the urgent moment." Pu Songling focused not on the terror fact but on the naked man and woman reaction to a serious earthquake, from which the author can be said to be a novelist who can make sense of life.

Hei gui is a story within only 91 words, like so-called social news today. Three parts of story seems to be pieced together at random, however, there is something amusing if they can be perceived as a whole. The first part of the story is about the impression of two black men, i.e., the pitchy black skin and the thick soles of the feet, and surprisingly that they could walk on a knife freely without any harm. The next case is the about the murder. A black man suspected that his son was not his own and killed him because his son's skin is white. But the result of test proved that was a mistake. The third case is the dancing party ordered by Gong in which the black men's appearance on their face looked strange. Prima facie, the three cases were narrated in terms of parallel and objective form. Nonetheless, if seen from the viewpoint of life experience, we will find that the three cases are really included in a succeeding deepened procedure and each case is connected with the others, especially, the dialectic relation between the last two cases concerning two different contrastive emotions, i.e., the horror arose by the black man's killing his own son and his beauty in a party. If the two cases were pieced together as a continuous whole, a strange or mysterious sense will arise somehow, which is very like the effect of montage used in cinema. It is just because Pu Songling could use generally contradictory dialectics that the Liao zhai stories like xi yi, hei gui are short in form, but the effect is as impressive as the longer stories concerning the supernatural powers. 


\section{Conclusion}

So far, it can be said that Liao zhai zhi yi has provided an important example for the Chinese novelists how to write a beautiful story by means of dialectics rather than with the help of poetry. It is regrettable that because Liao zhai is limited by its language of wen yan so that it is known to popular people only for the bizarre images and love story rather than its narrative arts. It is until late Qing Dynasty, under the influence of the conception of western literature, that modern Chinese writer began to study how to write a good story in terms of genre of novel. Actually, up to now, most of Chinese writers still think the western novels as their learning model. Therefore, it is worthwhile to study further Pu Songling's contributions in art to Chinese literature.

\section{References}

Chan, Wing-Tsit. (Trans. \& Ed.). (1963). A Source Book in Chinese Philosophy. Princeton: Princeton University Press. Heidegger, Martin. (1971). Poetry, Language, Thought. (Albert Hofstadter, Trans.). New York: Harper \& Row, Publishers. Pu, Songling. (2010). Strange Tales from a Chinese Studio. (Herbert A. Giles, Trans.). HK: Tuttle Publishing.

Pu, Songling. (2011). Complete Works of Liao zhai zhi yi. Zhang Youhe, (Ed.). Shanghai: Shanghai Chinese Classics Publishing House.

Kong, Lingjing. (1982). Historical Materials of Chinese Novels. Shanghai: Shanghai Chinese Classics Publishing House. Wang, Guowei. (1960). Ren Jian Ci Hua. Beijing: People’s Literature Publishing House. 